\title{
Eğitsel Web Arayüz Tasarımında Metaforlar: EMMA Adimları
}

\author{
Mehmet FIRAT ${ }^{1}$, Iș1 Kabakçı YURDAKUL ${ }^{2}$ \\ ${ }^{1}$ Uzaktan Öğretim Bölümü, Açıköğretim Fakültesi, Anadolu Üniversitesi, Eskişehir Türkiye \\ ${ }^{2}$ Bilgisayar ve Öğretim Teknolojileri Öğretmenliği Bölümü, Eğitim Fakültesi, Anadolu Üniversitesi, Eskişehir Türkiye \\ mfirat@anadolu.edu.tr, isilk@anadolu.edu.tr \\ (Geliş/Received: 11.01.2014; Kabul/Accepted: 29.01.2015) \\ DOI: $10.17671 /$ btd. 57664
}

\begin{abstract}
Özet - Doğrusal olmayan, hareketli ve esnek yapısıyla Hiperortamlar e-öğrenmenin temelini oluşturmaktadır. Öğrenen için geniş bir hareket esnekliği sağlayan Hiperortamlar birbirinden farklı çok sayıda eğitsel çoklu ortam materyaline ulaşma olanağı sağlamıştır. Ancak Hiperortamların öğrenen kontrolü için sağladığı bu esneklik ve enformasyon bolluğu, öğrenenin eğitsel Hiperortamdaki gezinim performansını olumsuz yönde etkileyen kaybolma, aşırı bilişsel yüklenme, dikkat bölünmesi ve zaman kaybı gibi gezinim problemlerini de beraberinde getirmiştir. Bu problemlerle başa çıkmak için eğitsel hiper ortamlarda doğal modeller olarak metaforlardan yararlanılabileceği düşünülmektedir. Çünkü metaforlar tanıdık olgular, alışkanlıklar, görevler ve somut nesnelerden yararlanarak ortamın fonksiyonlarını kullanıcıya anlaşılır ve hatırlanabilir hale getirebilirler. Bu çalışmada araştırmacılar tarafından 2009-2013 yılları arasında dört yıl süren araştırma sonuçlarından yararlanılmıştır. Yapılan araştırmalar sonucunda EMMA (Eğitsel içerik analizi, Metaforlar, Metaforik arayüz bileşenleri, Arayüz Tasarımı) Adımları adlı bir metaforik arayüz tasarım geliştirme çerçevesi belirlenmiştir. Bu çalışmada EMMA Adımlarının yapısı ve işleyişiyle birlikte pedagojik ve pratik çıkarımları sunulmuştur.
\end{abstract}

Anahtar Kelimeler - Hiperortam, Web, arayüz tasarımı, eğitsel arayüz tasarımı, bilişsel yük, kaybolma, metaforlar, gezinim performans1

\section{Metaphors in Educational Web Interface Designs: EMMI Steps}

\begin{abstract}
Hypermedia forms the basis of the e-learning with the active, non-linear and flexible structure. It provides a wide flexibility of movement for the learners. This allows access to a large number of educational multimedia materials. However, this learner control flexibility provided by hypermedia and abundance of information also have led to the emergence of disorientation, cognitive overload, divided attention and waste of time problems which negatively affect learner navigation performance. To cope with these problems it is expected to benefit from the metaphors as natural models in educational hypermedia. Because the metaphors may make the environment understandable and memorable to the user advantage of the concrete object, familiar facts, habits and tasks. The results from metaphorical interface design studies conducted over a 4 year period (2009-2013), provided the basis for this study. Based on the results of research a metaphorical interface design framework named EMMI (educational content analysis, metaphors, metaphorical interface components, Interface Design) has been developed. In this study, the pedagogical and practical implications are presented with the structure and operation of the framework.
\end{abstract}

Keywords - Hypermedia, Web, interface design, educational interface design, cognitive load, disorientation, metaphors, navigation performance

\section{GİRIŞ (INTRODUCTION)}

Bilişim teknolojilerinin 1990'lardan itibaren gösterdiği ilerleme bireyin başta Web ortamları olmak üzere elektronik öğrenme (e-öğrenme) araç ve ortamlarından yaygın olarak faydalanmasını sağlamıştır. $\mathrm{Bu}$ durum Jacobs'un [1], 20 yıl önce "yakın gelecekte eğitimde bir Hiperortam devrimi bekliyoruz" öngörüsünü doğrular niteliktedir. Bloglar, wikiler, öğrenme yönetim sistemleri, içerik yönetim sistemleri, e-kitaplar, eğitsel simülasyonlar, 
eğitsel oyunlar, 3D sanal dünyalar, video dersler, sanal sınıflar, Web 2.0 araçları, öğrenme nesneleri ve video konferanslar gibi e-öğrenme ortam ve araçları eğitim uygulamalarında basılı materyallerin önüne geçerek daha yoğun olarak kullanılmaya başlanmıştır [2]. Tüm bu eöğrenme araç ve ortamlarının öğrenene sunulması görevini ise Web ortamları, yani Hiperortamlar üstlenmiştir. Web'in kendisi de Hiperortam uygulamaları için en iyi örneklerden biri olarak gösterilebilir. Çünkü Web'in dünya çapında sahip olduğu ağın oluşmasında Hiperortamların sağladığı bağlantılar büyük önem taşımaktadır. Hiperortamlar, linkler sayesinde birbirine bağlı çoklu ortam düğümlerini kullanarak bilgiye ulaşma, düzenleme ve yapılandırma olanağı sağlayan benzersiz sistemlerdir [3].

Hiperortamlar düğümler arasında kurdukları bağlantılar sayesinde bir ağ yapısı kazanırlar [4]. Kitaplarda sayfa çevirmenin yerine dijital ortamda gezinme ortaya çıkmıştır. Bu nedenle Hiperortam ağı içerisinde düğümler arasında verilen bağlantılar yoluyla gezinmek çoğu Hiperortam sisteminde enformasyon erişiminin birincil yolu olarak görülmektedir. $\mathrm{Bu}$ da öğrenene öğretim ortamında oldukça esnek ve özgür bir yapı sunmaktadır. Burada esneklik ile vurgulanmak istenen öğrenene zaman, mekan ve medya açısından bağımsız seçeneklerin sunulmasıdır. Ancak bu esnek ve özgür yapı, üstbilişsel bir çaba gerektirmesiyle öğrenen için bazı zorlukları da beraberinde getirmektedir. Diğer bir ifadeyle Hiperortamlarda, kullanıcıya esnek ve özgür bir yap1 sunulmakla birlikte hangi içeriğe ne zaman ve hangi yoldan ulaşılacağı kullanıcının kendi inisiyatifine bırakılmıştır [5]. $\mathrm{Bu}$ bağlamda eğitsel Hiperortamlar da öğrenenin öğrenilmesi gereken içerik ve öğrenme yollarıyla ilgili kendilerinin seçim yapıp karar vererek kendi öğrenme süreçlerini kontrol etmesini gerektirmektedir.

Hareketli ve doğrusal olmayan yapısıyla Hiperortamlar, öğrenen için geniş bir hareket esnekliği, birbirinden farklı çok sayıda eğitsel çoklu ortam materyaline ulaşma olanağ 1 sağlamıştır. Ancak Hiperortamların öğrenen kontrolü için sağladığ öğrenenin eğitsel Hiperortamdaki gezinim performansını olumsuz yönde etkileyen kaybolma, aşırı bilişsel yüklenme, dikkat bölünmesi ve zaman kaybı gibi gezinim problemlerini de ortaya çıkarmıştır [5], [6]. Bu problemler başa çıkmak için ise tanıdık olgular, alışkanlıklar, görevler ve somut nesnelerden yararlanarak ortamın fonksiyonların kullanıcıya anlaşılır ve hatırlanabilir hale getiren metaforlardan yararlanılabileceği savunulmaktadır. Bu savı desteklemek amacıyla araştırmacılar tarafından 2009 ile 2012 yılları arasında dört yıl boyunca süren araştırma sonuçlarından yararlanılmıştır. Yapılan araştırmalar sonucunda EMMA Adımları adlı bir metaforik arayüz tasarım geliştirme çerçevesi geliştirilmiştir. Bu çalışmada oluşturulan çerçevenin yapısı ve işleyişiyle birlikte pedagojik ve pratik çıkarımları sunulmuştur.

\subsection{Ilgili Alanyazın (Related Literature)}

Alanyazında metaforların arayüzlerde kullanılmasına ilişkin çeşitli araştırmalar bulunmasına karşın metaforların eğitsel arayüzlerde kullanılması ve bu arayüzlerin etkililiklerinin incelenmesine yönelik çalışmaların yetersiz olduğu görülmektedir [7]. Bunun yanında ilgili alanyazında metaforların eğitsel arayüzlerde kullanılmasını konu alan herhangi bir arayüz tasarım modeli, yapısı veya çerçevesi bulunmamaktadır. $\mathrm{Bu}$ noktada bir ilk olması açısından araştırma özgün bir değere sahiptir.

Hiper metin, Hiperortam ve çoklu ortamlarda kullanıcıların yeni çevrelere alışmalarını kolaylaştırmak için yine metaforlara başvurulmuştur. Çünkü arayüzde kullanılan metaforlar tanıdık olgular, alışkanlıklar, görevler ve somut nesnelerden yararlanarak ortamın görünmeyen soyut fonksiyonlarını kullanıcıya anlaşılır ve hatırlanabilir hale getirmeyi amaçlamaktadır. Metaforlar tanıdık ve sağlam objelerden bilgileri almamızı sağladıkları ve doğal modeller gibi işlev gördükleri için Hiper metin ve Hiperortamlardaki kullanımları oldukça önemlidir.

Arayüzlerde metafor kullanımıyla ilgili ilk çalışmalar arasında yer alan Apple firmasının sunduğu e-World hizmeti dikkat çekicidir. 1994 yılında Macintosh bilgisayarlarda sunulmaya başlanan bu hizmet özgün bir metaforik arayüz temeline dayandırılmıştı. $\mathrm{Bu}$ ortamda kullanıcıya tanıdık ve rahat bir görünüm sağlamak için "Şehir" metaforundan yararlanılmıştır. Metaforik arayüze sahip bu ortam kullanıcılar için oldukça kullanışlı bir ortam sağlamış olsa da AOL, CompuServe ve MSN ile olan rekabeti kaybetmiş ve 1996 yılında kapatılmıştır.

Arayüzlerin temel rolü kullanıcı ile materyal arasındaki etkileşimi sağlamaktır. İşlevsel, etkileşimi destekleyen ve estetik açıdan uygun arayüzler öğrenenlerin öğrenme aktivitelerine yoğunlaşma noktasında önemli rol oynarlar. Öncelikle ilgi çekici, etkili ve verimli arayüzler, öğrencilerin dikkat ve ilgilerini çekebilir, öğrenci ile öğrenme materyali arasındaki etkileşimi destekleyebilir, öğrencilerin algılama, düzenleme, bütünleştirme ve hatırlama becerileri için bir platform oluşturabilirler [10]. $\mathrm{Bu}$ nedenle öğretim tasarımcıları için etkili, verimli ve estetik açıdan uygun arayüzler tasarlamak önemli bir görevdir.

Temelde metaforik arayüzler, günlük deneyim dünyasından çıkarılan görsel ve işlevsel metaforlar ile oluşturulacak ortamın olanak ve işlevlerinin kullanıcıların yönlendirilmesine yardımc olmak amaciyla birleştirilmesinden oluşurlar [8]. Nispeten yeni bir kavram olan metaforik arayüzler genelde verilen içerikle ilgili görsel metaforun veya metaforların ortamla etkileşimi sağlayan bileşenlerde kullanılması şeklinde 
tasarlanmaktadırlar [7]. Metaforik arayüzlerin içerdikleri resimler ve diğer çoklu ortam bileşenleri doğrudan tanımlardan, kavram veya deyimlerden daha çok anlam taşıyabilirler. Çünkü metaforlar, kullanıcıların yeni bilgileri uygun şemalar içinde daha kolay özümsemelerini sağlarlar. Gerçekleştirdikleri deneysel çalışmaları sonucunda Lee ve Hsu [9] görsel metaforik arayüzlerin öğrenci öğrenme performansını artırdığını bulgulamışlardır.

Arayüzde metafor kullanımı ile ilgili gerçekleştirilen diğer bir araştırmada arayüzlerde panoramik etkileşimi gerçekleştirmek amacıyla metaforlardan yararlanmışlardır [19]. Araştırmada kullanıcıların 2d ve 3d ortamlarda verileri görselleştirmek amaciyla çeşitli araçlardan yararlandıkları, bu görselleştirme araçlarıyla veride arama, zoom ve filitre yaptıkları, bu görselleştirme araçlarıyla etkileşime geçtikleri vurgulanmıştır. Anket çalışmasıyla öncelikle arayüz etkileşim boyutları belirlenmiş ve anket sonuçlarına göre metaforik bir arayüz tasarlanmıştır. Geliştirilen arayüzün teknik incelemeleri sonucunda kullanıcı performansına katkı sağlayacağı sonucuna varılmıştır. Ayrıca araştırma sonucunda metaforların arayüzlerde etkili bir şekilde kullanılabileceği vurgulanmıştır. Yine arayüzlerde metafor kullanımıyla ilgili diğer bir çalışmada ise CAVE adlı meteoroloji, manyetik alan, kasırga, gelgit dalgaları veri görüntüleme platformu için "balık tutma" metaforundan yararlanılarak bir arayüz tasarımı geliştirilmiştir [20]. Araştırmanın kapsamında geliştirilen "balık tutma" metaforik arayüzünün teknik incelemeleri sonucunda büyük verilerin görselleştirilmesinde daha iyi bir performans ve potansiyele sahip olduğu sonucuna varılmıştır. Ancak bu iki araştırmada da geliştirilen arayüzler herhangi bir hedef kitleye uygulanmamış, sadece geliştirilen arayüzler teknik açıdan incelenmiştir.

Metaforların kullanılış biçimine göre metaforik arayüzleri konusal (tematic) ve yerleşik (immersive) metaforlar olmak üzere iki kategoride incelemek mümkündür [10]. Konusal metaforik arayüzlerde kullanılan metaforlar içeriği tam olarak yansıtmazlar ancak ev, kitap gibi kullanıcıya tanıdık metaforlarla desteklerler. Metaforik arayüz tasarımlarında hem konusal hem de yerleşik metaforlar farklı amaçlarla kullanılabilmektedir. Bununla birlikte metaforik arayüz tasarımlarında görsel tasarımı destekledikleri için yerleşik metaforların daha sık kullanıldıklarını söylemek mümkündür. Diğer taraftan yerleşik metaforik arayüzlerde ise çeşitli işaretler ve ipuçlarıyla birlikte verilen içeriğin kapsamını yansıtan gerçekçi ortamlar oluşturulur. Konusal metaforik arayüze, British Musium'un zaman tüneli şeklinde tasarlanan dünya tarihi uygulaması örnek verilebilir. Bu arayüzde dünya tarihi konusu metaforun kaynak konusunu zaman tüneli ise hedef konuyu ifade etmektedir. Ancak arayüzde bu kavramsal metafor temeline dayanan temel yapının dışında metaforlar bulunmamaktadır. Așağıda Şekil 1'de zaman tüneli uygulamasının metaforik arayüzü verilmiştir.

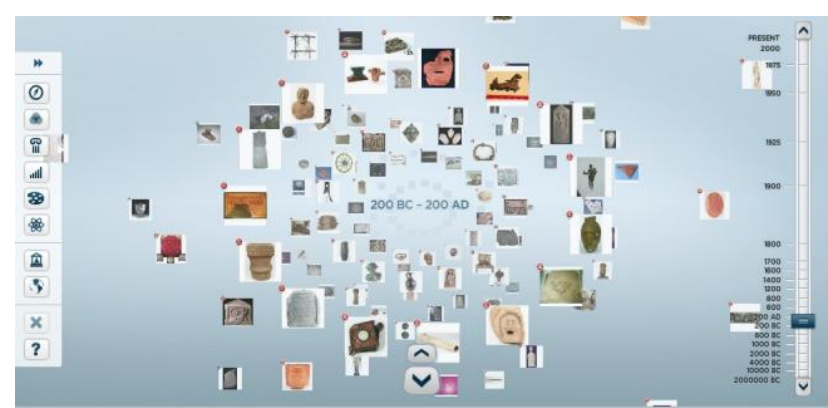

Şekil 1. British Musium'un “Zaman Tüneli” Metaforu (British Musium the "Time Tunnel" Metaphor)

Yerleşik metaforik arayüze örnek olarak da yine British Musium'un bir çalışma odası şekline tasarlanan Muglian India uygulaması örnek verilebilir. Aşağıda Şekil 2'de Muglian India uygulamasının metaforik arayüzü verilmiştir.

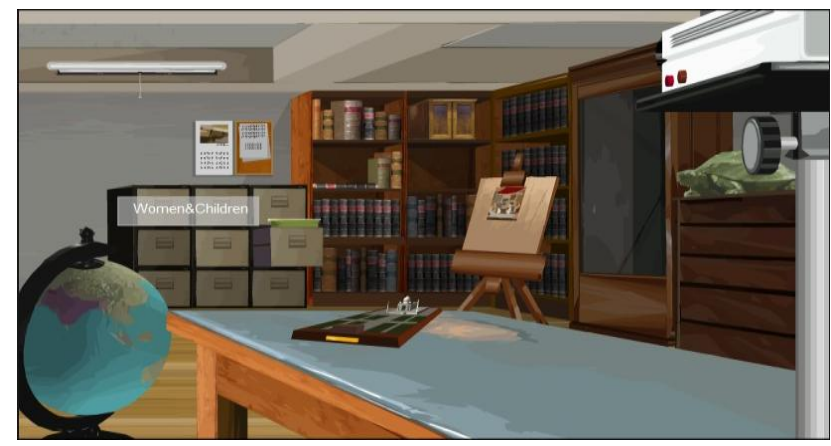

Şekil 2. Muglian India Hiperortam Uygulamas1 (British Musium the "Time Tunnel" Metaphor)

Çalışma odasının bileşenleri olan araçları, çeşitli işaretler ve ipuçları sağlarken ortamın bütünü gerçekçi bir ortamı yansıtabilir. $\mathrm{Bu}$ araştırmada da yerleşik metaforik arayüzlerden yararlanılmıştır. British Musium'un çalışma odası metaforuna dayanan Muglian India uygulamasının arayüzünde de görüldüğü gibi çalışma odası tümleşik (kompozit) metaforu içerisinde kitaplık, çekmeceler, takvim ve diğer bileşenler de uygun konular için birer metafor olarak tasarlanmışlardır.

\subsection{Metaforlar (Metaphors)}

Eğitimde yaygın olarak kullanılan e-öğrenme uygulamalarının Hiperortamlar yoluyla sunulması ögrenene zaman ve mekândan bağımsız, öğrenci merkezli ve esnek öğrenme ortamlarıyla firsat eşitliği sunmaktadırlar. Ancak etkili bir öğrenme ortamı oluşturmak için sadece eğitsel içerik ve öğrenme etkinliklerine odaklanılmamalı aynı zamanda kullanıcı arayüzlerinin tasarımına da dikkat çekilmelidir [11]. Hipersistemler, bireylerin kendi öğrenme süreçlerini kontrol altında tutabilecekleri, kararlar alabilecekleri ve birbirleriyle iletişim içerisinde bulunabilecekleri ortamlar sunabilirler. Ancak Hiperortamların sağladığı bu esneklik öğrenenin kendi kendine öğrenme sorumluluğunu da arttırmıştır. Bu da öğrenenin Web ortamlarında kaybolma, 
aşırı bilişsel yüklenme, dikkat bölünmesi, sürekli kısmi dikkat, zaman kayb1 ve motivasyon kayb1 gibi problemlerle karşılaşmasına neden olmaktadır. Bu noktada öğrenenlerin belirtilen problemlerle başa çıkabilmeleri için metaforik arayüzlerden yararlanılabileceği savunulmaktadir.

Gündelik hayatın hemen her alanında kullandığımız metaforlar 1980'lere kadar çoğunlukla rötarik veya dili etkili bir şekilde kullanma tekniği olarak ele alınmış ve sözcükleri gerçek anlamları dışında kullanma sanatı ya da ad değişimi olarak tanımlanmışlardır. Klasik metafor anlayışı yüzyıllar boyunca o kadar yerleşik ve sıradan kullanılmıştır ki çoğu zaman bu yaklaşımın sadece bir kuram olduğu göz ardı edilmiştir [12].

Ancak 1980'de iki bilişsel bilimci olan George Lakoff ve Mark Johnson'nun "Metaphors We Live By" adl çalışmalarında metaforların bilişsel yönlerinin önemini "Kavram sistemimiz büyük ölçüde metaforikse, o zaman düşünme tarzımız, tecrübe ettiğimiz her olgu ve günlük olarak yaptığımız her şey bir bakıma metaforiktir” şeklinde açıklamışlardır [13]. Burada vurgulanmak istenen metaforların sadece dilde değil düşünmede ve eylemde yoğun olarak kullanılan yapılar olduğudur. Lakoff ve Johnson'a göre metafor, bir tür şeyi başka bir tür şeye göre anlamak ve tecrübe etmektir. Metafor kavramını tam olarak ifade edilemeyen bir benzerliği ifade etmek için içinde bir şeye atıfta bulunma anlatımı olan söz söyleme biçimi şeklinde tanımlamak mümkündür.

Metaforik bir ifadenin asıl ve yardımcı olmak üzere iki yarı konusundan bahsetmek mümkündür. Örneğin "insan vücudu makinedir" metaforunda "insan vücudu" asıl konuyken "makine" yardımcı konumundadır. Burada metaforun fonksiyonu yardımcı konuya ilişkin yaygın özellikleri asıl konuya uygulanmasıdır. Yani normalde yardımcı konuya ait olan ifadelerle asıl konunun özellikleri seçilmiş, düzenlenmiş ve vurgulanmış olur. Alanyazında yapılan araştırmalarda kaynak ile hedef arasındaki benzerlik derecesinin metaforların kabiliyet ve yorumlanabilirlikleri ile pozitif yönde ilgili olduğu tespit edilmiştir [14]. Metafor anlaşılma ya da yeniden yapılanma ihtiyacı olan bir etki alanı içine tanıdık bir alan deneyimlerine ait açıklayıcı yapıları taşıyarak yapısal benzerlikleri görünür hale getirir ve böylece hedef alan için herhangi bir yapısal benzerliğin çok ötesinde bir organizasyon sağlanmış olur [13]. Bu bağlamda metaforların doğal bir ön örgütleyici rolü üstlenerek pedagojik açıdan geniş bir potansiyele sahip olduğunu söylemek mümkündür. $\mathrm{Bu}$ çerçevede metaforların pedagojik boyutu temelinde araştırmacılar tarafindan 2009-2012 tarihleri arasında gerçekleştirilen çalışmaların sonuçları bu araştırmada verilmiştir.

\subsection{Amaç (Purpose)}

$\mathrm{Bu}$ araştırmanın amacı eğitsel Hiperortam arayüzlerinde öğrenenlerin kaybolma ve aşırı bilişsel yüklenme gibi Web gezinim problemleriyle başa çıkmalarını sağlayan metaforik arayüzlerin geliştirilmesi, uygulanması ve değerlendirilmesi süreçlerini ortaya koyacak bir eğitsel arayüz tasarım çerçevesi oluşturmaktır. $\mathrm{Bu}$ amaç doğrultusunda araştırmada cevabı aranan sorular şunlardır;

- görsel metaforlar öğrenenlerin hiperortamdaki gezinim performansını etkiler mi?

- eğitsel hiperortamlarda gezinim performansı değişkenleri nelerdir?

- metaforik arayüzlerin öğrenenlerin gezinim performansina etkileri nelerdir?

- eğitsel hiperortamlarda metaforik arayüzler oluşturulurken izlenebilecek adımlar nelerdir?

- eğitsel hiperortamlarda metafor kullanımının pedagojik ve pratik çıkarımları nelerdir?

\section{YÖNTEM (METHOD)}

Gerçekleştirilen araştırmada eğitsel Hiperortamlarda metaforik arayüzlerin geliştirilmesi, uygulanması ve değerlendirilmesi süreçlerini ortaya koyacak bir eğitsel arayüz tasarım çerçevesinin oluşturulması amaçlanmıştır. $\mathrm{Bu}$ amaç doğrultusunda araştırmacılar tarafından eğitsel arayüzde metafor kullanımına ilişkin 2009-2012 yılları arasında gerçekleştirdikleri bir dizi araştırmanın sonuçlarından yararlanılmıştır. Yapılan çalışmalar aşağıda Tablo 1'de verilmiştir.

Tablo 1. Yapılan Araştırma Ayrıntıları

(The table title should be short and concise)

\begin{tabular}{|c|c|}
\hline Yayın & Başlık \\
\hline $\begin{array}{l}\text { Uluslararas1 } \\
\text { Hakemli } \\
\text { Dergide Makale }\end{array}$ & $\begin{array}{l}\text { Use of Visual Metaphors for Navigation in Educational } \\
\text { Hypermedia: Effects on the Navigational Performance } \\
\text { (Eğitsel Hiperortamlarda Gezinim için Görsel Metafor } \\
\text { Kullanımı: Gezinim Performansına Etkiler) [6]. }\end{array}$ \\
\hline $\begin{array}{l}\text { Uluslararas1 } \\
\text { Kitapta Kitap } \\
\text { Bölümü }\end{array}$ & $\begin{array}{l}\text { Metaphors in Meta-Communication (Meta-iletişimde } \\
\text { metaforlar). Meta-communication for Reflective Online } \\
\text { Conversations: Models for Distance Education [15]. }\end{array}$ \\
\hline $\begin{array}{l}\text { Uluslararası } \\
\text { Hakemli } \\
\text { Dergide Makale }\end{array}$ & 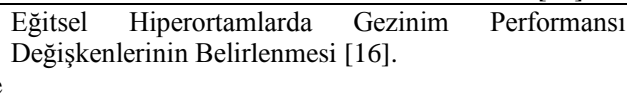 \\
\hline Doktora Tezi & $\begin{array}{l}\text { Eğitsel Hiperortamlarda Metaforik Arayüzlerin Bilişim } \\
\text { Teknolojileri Öğretmen Adaylarının Gezinim } \\
\text { Performansına Etkileri [17]. }\end{array}$ \\
\hline
\end{tabular}

$\mathrm{Bu}$ araştırmalarda çeşitli hedef kitlelerle farklı tasarımlar çalışılmış ve bu amaçlı çeşitli araştırma yöntemlerinden yararlanılmıştır. Görsel metaforlarla desteklenen Hiperortam arayüzlerinin Bilişim Teknolojileri öğretmen adaylarının hiper ortamdaki gezinim performanslarına etkilerini belirlemek amaciyla 33 lisans öğrencisiyle gerçekleştirilen araştırmada gerçek deneme modellerinden son-test kontrol gruplu modelden yararlanılmıştır. Eğitsel Hiperortamlarda gezinim performansı değișkenlerini belirlenmek amaciyla 26 Bilişim Teknolojileri alan 
uzmanıyla gerçekleştirilen araştırmada genel tarama modellerinden biri olan tekil tarama modelinden yararlanılmıştır. Eğitsel Hiperortamlarda metaforik arayüzlerin bilişim teknolojileri öğretmen adaylarının gezinim performansına etkilerini belirlemek amacıyla gerçekleştirilen doktora tezinde ise karma yöntem araştırmasından yararlanılmıştır. Araştırma süresince toplamda 47 Bilişim Teknolojileri alan uzmanı ve 370 Bilişim Teknolojileri öğrencisiyle çalışılmıştır.

\section{BULGULAR (RESULTS)}

$\mathrm{Bu}$ araştırmada elde edilen bulgular bu başlık altında verilmiştir. Araştırmalardan elde edilen bulgular araştırma sorularına göre verilmiştir.

\subsection{Görsel Metaforlar Öğrenenlerin Hiperortamdaki Gezinim Performansinı Etkiler Mi? (Does Visual Metaphors Affects Navigation Performance of Learner in Hypermedia?)}

Görsel metaforların eğitsel Hiperortamlarda kullanımına yönelik araştırma Fırat ve Kabakçı tarafından görsel metaforların eğitsel Hiperortamlarda öğrenenlerin gezinim performanslarına olan etkileri belirlemek amacıyla gerçekleştirilmiştir [6]. Anadolu Üniversitesi'nden 33 lisans öğrencisiyle gerçekleştirilen araştırmada aynı içeriğe sahip biri metaforik arayüze sahip olan diğeri metaforik arayüze sahip olmayan iki Hiperortam oluşturulmuştur. $\mathrm{Bu}$ iki Hiperortam aşağıda Şekil 3 ’te verilmiştir.

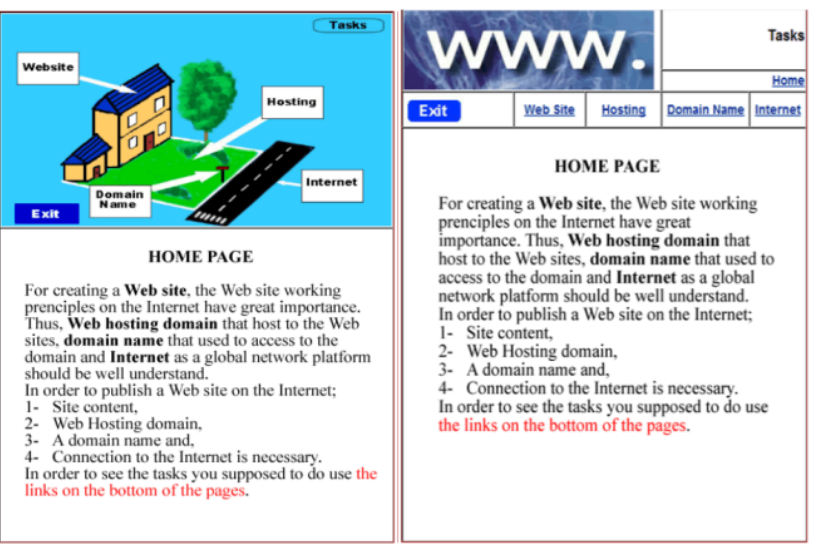

Şekil 3.Hiperortam Arayüzleri

(Hypermedia Interfaces)

$\mathrm{Bu}$ ortamlardan ilkinin (solda) geziniminde görsel metafordan yararlanılmış, diğerinde (sağda) geleneksel metin bağlantıları kullanılmıştır. Araştırma son-test kontrol gruplu modelde desenlenmiştir. Araştırmada kaybolma, zaman ve katılımcıların kendi gezinim performansı değerlendirmeleri olmak üzere üç farklı gezinim performansı ölçümü yapılmıştır. Araştırmadan elde edilen bulgulara göre görsel metaforların kullanıldı ğ Hiperortamda ögretmen adaylarının gezinim performansı görsel metaforların kullanılmadığı Hiperortama göre daha yüksek çıkmıştır.

\subsection{Eğitsel Hiperortamlarda Gezinim Performansı} Değișkenleri Nelerdir? (What are the Navigation Performance Factors in Educational Hypermedia)

Bilişim Teknolojileri alan uzmanlarının görüşüne dayanarak eğitsel Hiperortamlarda gezinim performansı değişkenlerini belirlemek amacıyla Fırat ve Kabakçı tarafından bir araştırma gerçekleştirilmiştir [16]. Bu amaç doğrultusunda veri toplama aracı olarak geliştirilen bir anket formu kullanılmıştır. Araştırmanın katılımcılarını 26 Bilişim Teknolojileri alan uzmanı oluşturmaktadır. Araştırmadan elde edilen bulgulara göre alan uzmanları başta kaybolma ve bilişsel yük olmak üzere zaman, motivasyon ve memnuniyet değişkenlerini öğrenenin eğitsel Hiperortamda gezinim performansının açık birer göstergesi olarak görmüşlerdir. Aşağıda Şekil 4'te Fırat ve Kabakçı Yurdakul tarafından metaforik arayüz olarak kullanılan durağan metaforik görsellerden oluşan bir Hiperortam arayüzü örneği verilmiştir [15].

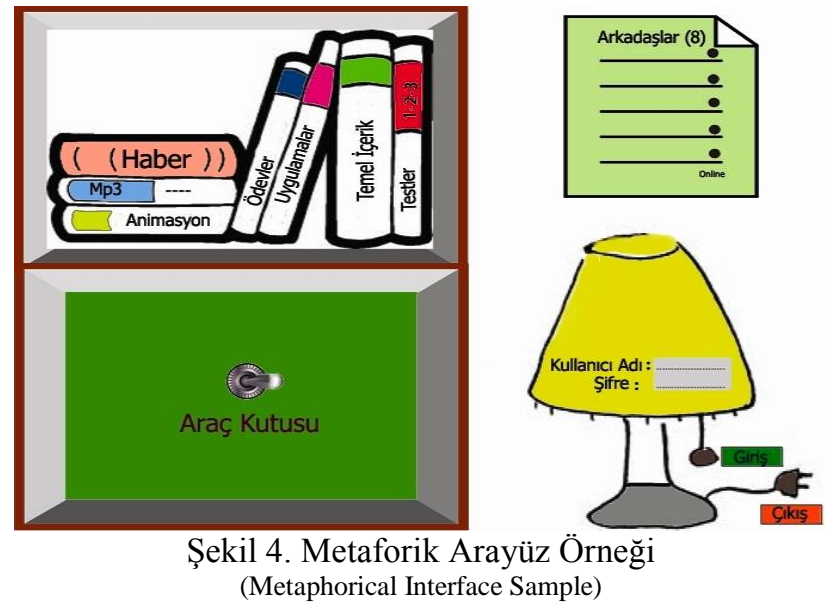

Şekil 4'te de görüldüğü gibi arayüzde kitaplık, lamba ve takvim metaforlarından yararlanılmıştır. Kitaplık ders materyallerinin verilmesinde, lamba kullanıcı giriş çıkış kontrollerinde, takvim ise chat uygulamasinın gösteriminde kullanılmıştır. Arayüzün bu bileşenleri kitaplık, takvim ve lamba metaforlarıyla oluşturularak ortamın kullanıcıya tanıdık olması sağlanmaya çalışılmıştır.

\subsection{Metaforik Arayüzlerin Öğrenenlerin Gezinim Performansina Etkileri Nelerdir? (What are the Effects of Metaphorical Interfaces on Learner Navigation Performance?)}

"Eğitsel Hiperortamlarda Metaforik Arayüzlerin Bilișim Teknolojileri Öğretmen Adaylarının Gezinim Performansına Etkileri” başlıklı doktora tezi kapsamında 2009-2012 yılları arasında arayüzde metafor kullanımına ilişkin kapsamlı araştırmalar yapılmıştır [17]. Araştırma süresince eğitsel Hiperortamlarda metaforik arayüzlerin Bilişim Teknolojileri (BT) öğretmen adaylarının gezinim performansları üzerindeki etkilerini belirlemek amaçlanmıștır. 
Araştırma kapsamında hazırlık çalışmaları süreci ve uygulama süreci olmak üzere iki aşama izlenmiştir. Hazırlı çalışmaları sürecinde uygulama öncesi gerçekleştirilen çalışmalar yapılmıştır. Uygulama öncesinde araştırmanın bağımlı değişkeni olan gezinim performansını etkileyen faktörlerin belirlenmesi, Gezinim Performansı ölçeğinin geliştirilmesi ve metaforik arayüzlerin geliştirilmesi çalışmaları yapılmıştır. Uygulama sürecinde ise eğitsel Hiperortamlarda verilen görevleri yerine getiren BT öğretmen adaylarına yönelik gözlem, HOGP ölçeğinin uygulanması ve son olarak öğretmen adaylarının gezinim performanslarına yönelik algılarına ilişkin odak grup görüşmesi yapılmıştır.

Karma yöntem araştırması olarak desenlenen tez çalışmalarının deneysel boyutunda eğitsel Hiperortamlarda metaforik arayüzlerin BT öğretmen adaylarının eğitsel Hiperortamlardaki gezinim performanslarına olan etkilerini belirlemek amaciyla son-test kontrol gruplu desenden yararlanılmıştır. Bağımsız değişkenler eğitsel Hiperortamın arayüz tasarımı (metaforik, metaforik olmayan) ve deneyim (2. Sınıf, 4. Sınıf) iken bağımlı değişkenler ise verilen görevleri yerine getirmek için harcanan zaman ve Hiperortamda gezinim performansı olarak belirlenmiştir.

Araştırmanın katılımcılarını 2011-2012 öğretim yılının bahar döneminde Anadolu Üniversitesi, Eğitim Fakültesi, Bilgisayar ve Öğretim Teknoloji Eğitimi Bölümü 2. Ve 4. Sınıfta öğrenim gören 76 Bilişim Teknolojileri öğretmen adayı oluşturmaktadır. Verilerinin toplanmasında araştırma kapsamında geliştirilen ve iç tutarlılık katsayısı $\alpha=.90$ olan Hiperortamlarda Gezinim Performansı Ölçeği, gözlem ve odak grup görüşmesinden yararlanılmıştır. Toplanan nicel verilerin analizinde bağımsız iki örneklem t-testi, tek yönlü ANOVA ve iki yönlü ANOVA testleriyle birlikte yüzde $(\%)$, ortalama $(\mathrm{X})$, frekans $(f)$ betimsel istatistiklerinden yararlanılmıştır. Elde edilen nitel verilerin analizinde ise betimsel içerik analizi ve tematik analizden yararlanılmıştır.

Araştırmadan elde edilen verilerin analizi sonucunda, metaforik arayüzlerin Bilişim Teknolojileri öğretmen adaylarının gezinim performansı üzerinde "yüksek" düzeyde anlamlı bir etkiye sahip olduğu görülmüștür $(\eta 2=.16)$. Metaforik arayüze sahip eğitsel Hiperortamlarda verilen görevleri yerine getiren 2. Ve 4. Sınıf Bilişim Teknolojileri öğretmen adayları metaforik olmayan arayüzde verilen görevleri yerine getiren öğretmen adaylarından daha yüksek gezinim performansı göstermişlerdir. Cinsiyet, internet kullanım sıklığı ve internet kullanım yeterliği gibi bağımsız değişkenlerin ise Bilișim Teknolojileri öğretmen adaylarının eğitsel Hiperortamlardaki gezinim performansı üzerinde yeterli etkiye sahip olmadığı belirlenmiştir.

Arayüz Tasarımlarının Geliştirilmesi: Araştırma kapsamında belirlenen geridönüşüm içeriğine yönelik uygun metaforların belirlenmesi çalışmasıyla BT öğretmen adaylarından 9 arayüz metaforu elde edilmiştir. Bunlar; Ağaç, Çöp kutusu, Elbise, İnsan, Kitap, Araba, Can simidi, Çamaşır makinesi ve Bilgisayar olarak belirlenmiştir. Bu metaforlardan yararlanılarak mağaza kompozit metaforuna ulaşılmıştır. Hiperortamın kompozit metaforik arayüz tasarımı aşağıda Şekil 5 'te verilmiştir.

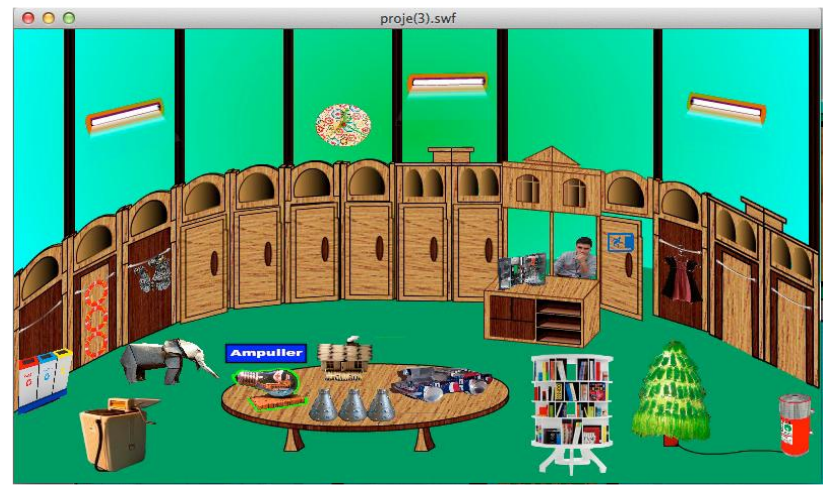

Şekil 5. Kompozit Metaforik Arayüz Tasarımı (Composite Metaphorical Interface Design)

Ekranda da görüldüğü gibi mağaza içerisindeki tüm bağlantılar, mağazanın içerisindeki eşyalardan oluşturulmuştur. $\mathrm{Bu}$ eşyaların her biri geri dönüşüm konusunda BT öğretmen adayları tarafindan oluşturulan ve "İlgi Alanları ve Metafor Belirleme Anketi" yoluyla toplanan metaforlardan üretilmiştir. Böylece BT öğretmen adaylarının oluşturduğu tüm metaforlar mağaza tümleşik metaforunda toplanmıştır. Araştırmanın kontrol grubu için hazırlanan eğitsel Hiperortam arayüzü ise Şekil 6'da verilmiştir.

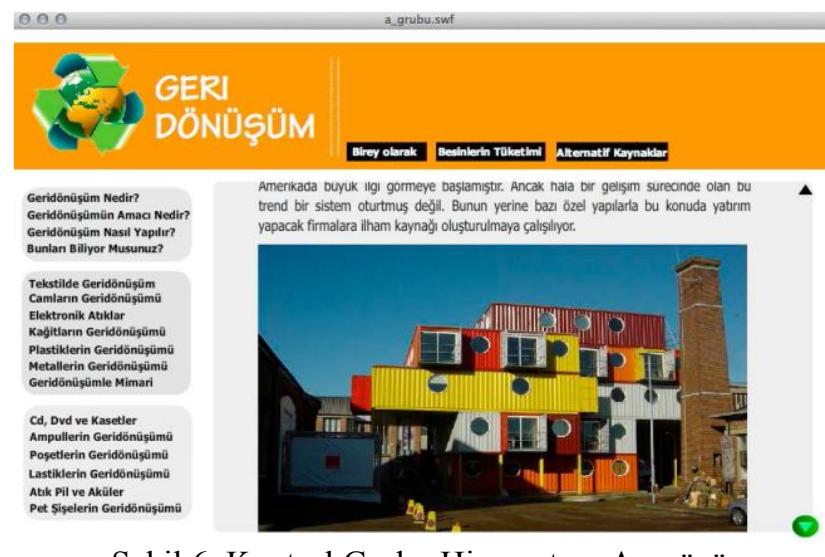

Şekil 6. Kontrol Grubu Hiperortam Arayüzü (Hypermedia Interface of Control Group)

Hem metaforik arayüze sahip Hiperortamda hem de metaforik arayüze sahip olmayan Hiperortamdaki içerikler aynen verilmiştir. Böylece öğrenenlerin eğitsel Hiperortamdaki gezinimini arayüz tasarımı dışındaki değişkenlerin etkisinin en aza indirgenmesi amaçlanmıştır. Gerçek uygulamada kullanılmak üzere tasarlanan Hiperortamların dışında, BT öğretmen adaylarının yeni ve farklı bir teknik olarak metaforik arayüzlere sahip 
Hiperortamlardaki gezinimleri üzerinde Howthorne etkisini gidermek amacıyla metaforik arayüze sahip başka bir eğitsel Hiperortamda tasarlanmıştır. Böylece araştırma katılımcılarının sunulan yeni ve farklı bir ortamda normalde sergiledikleri davranışlardan farklı davranış sergilemelerinin önüne geçilmeye çalışılmıştır. Howthorne etkisini azaltmak amaciyla geliştirilen ve gerçek uygulamadan iki hafta önce aynı katılımcı grubuna uygulanan eğitsel Hiperortam arayüzü Şekil 7'de verilmiştir.

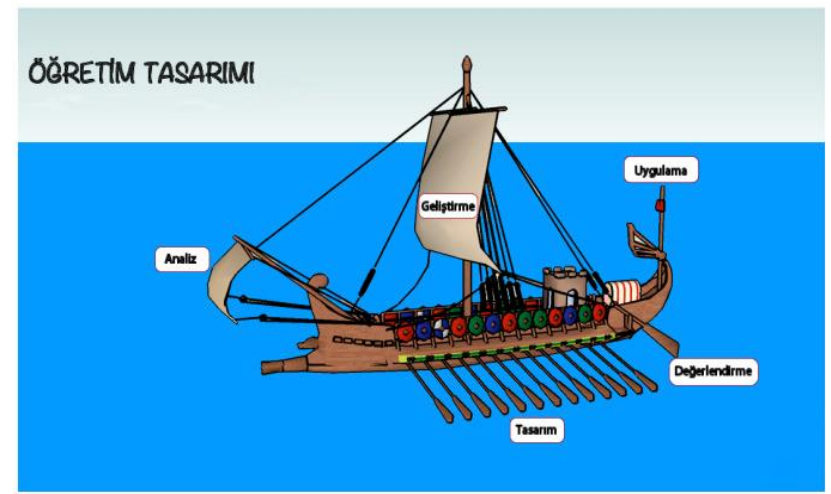

Şekil 7. Howthorne Etkisi İçin Arayüz Tasarımı (Interface Design for Howthorne Effect)

Araştırmada deney ve kontrol grubu için hazırlanan eğitsel Hiperortamlarda içerik olarak "Geri dönüşüm” konusu işlenmiştir. Kontrol grubu için hazırlanan arayüzde bağlantılar listelenmiş başlıklar halinde verilmiş, ilgili içerik ise ayrı bir içerik bölümünde verilmiştir. Deney grubu için hazırlanan arayüz ise tümleşik bir metafor olan mağaza metaforundan yararlanılarak tasarlanmıştır. Mağaza içerisindeki her bir nesne bir bağlantı olarak kullanılmıştır. Eğitsel Hiperortamlarda yapılan düzenlemelerle birlikte istenmeyen değişkenlerin etkilerini azaltmak amacıyla tüm gruplarla gerçekleştirilen uygulama aynı ortamda ve aynı zamanda gerçekleştirilmiştir. Bununla birlikte deney ve kontrol grupları için BT öğretmen adayları seçkisiz atamayla belirlenmiştir.

\subsection{Eğitsel Hiperortamlarda Metaforik Arayüzler Oluşturulurken İzlenebilecek Adımlar Nelerdir?}

$\mathrm{Bu}$ çalışmada sunulan EMMA (Eğitsel İçerik Analizi, Metafor Analizi, Metaforik Arayüz Bileşenleri, Arayüz Tasarımı) Adımları metaforik arayüzler ve gezinim performansına yönelik 3 yıl boyunca gerçekleştirilen çeşitli araştırmalara dayanmaktadır. Araştırmalar kapsamında geliştirilen metaforik arayüzlerin tasarım süreci dikkate alınarak eğitsel Hiperortamlarda metaforik arayüzler oluşturulurken izlenebilecek adımlara yönelik bir çerçeve yapı sunmak mümkündür. Her biri kendi içinde özgün bir yapıya sahip bu adımlar araştırma süresince yapılan alanyazın taraması, hedef kitle ve uzman görüşleri ile doğrudan hedef kitleyle yapılan uygulamalar sonucunda geliştirilmiştir. Eğitsel metaforik arayüzlerin tasarımı sürecinde izlenmesi önerilen adımlar Tablo 2'de verilmiştir.

Tablo 2. Eğitsel Metaforik Arayüzlerin Tasarımı Sürecinde İzlenmesi Önerilen Adımlar

(Recommended Steps Educational Metaphoric Interface Process)

\begin{tabular}{lll}
\hline No & Aşama & Çalışılan Gurup \\
\hline 1. Aşama & Eğitsel İçerik Analizi & $\begin{array}{l}\text { Hedef Kitle ve Alan } \\
\text { Uzmanları }\end{array}$ \\
\hline 2. Aşama & Metafor Analizi & Hedef Kitle \\
\hline 3. Aşama & Metaforik Arayüz Bileşenleri & Hedef Kitle \\
\hline 4. Aşama & Arayüz Tasarımı & $\begin{array}{l}\text { Hedef Kitle ve Ö̆ğretim } \\
\text { Tasarımcısı }\end{array}$ \\
\hline
\end{tabular}

Araştırma kapsamında uygulanan ve metaforik arayüz tasarımında izlenebilecek bu dört adımdan yola çıkarak EMMA isimli bir çerçeve yapı oluşturulmuştur. EMMA, yapıdaki her bir adımın ilk harflerinin birleştirilmesiyle oluşturulmuştur. EMMA'nın çerçeve yapısı, içerdiği dört temel adım ve her bir adimda cevaplanması gereken sorulara yönelik bilgiler aşağıda Şekil 8'de verilmiştir.
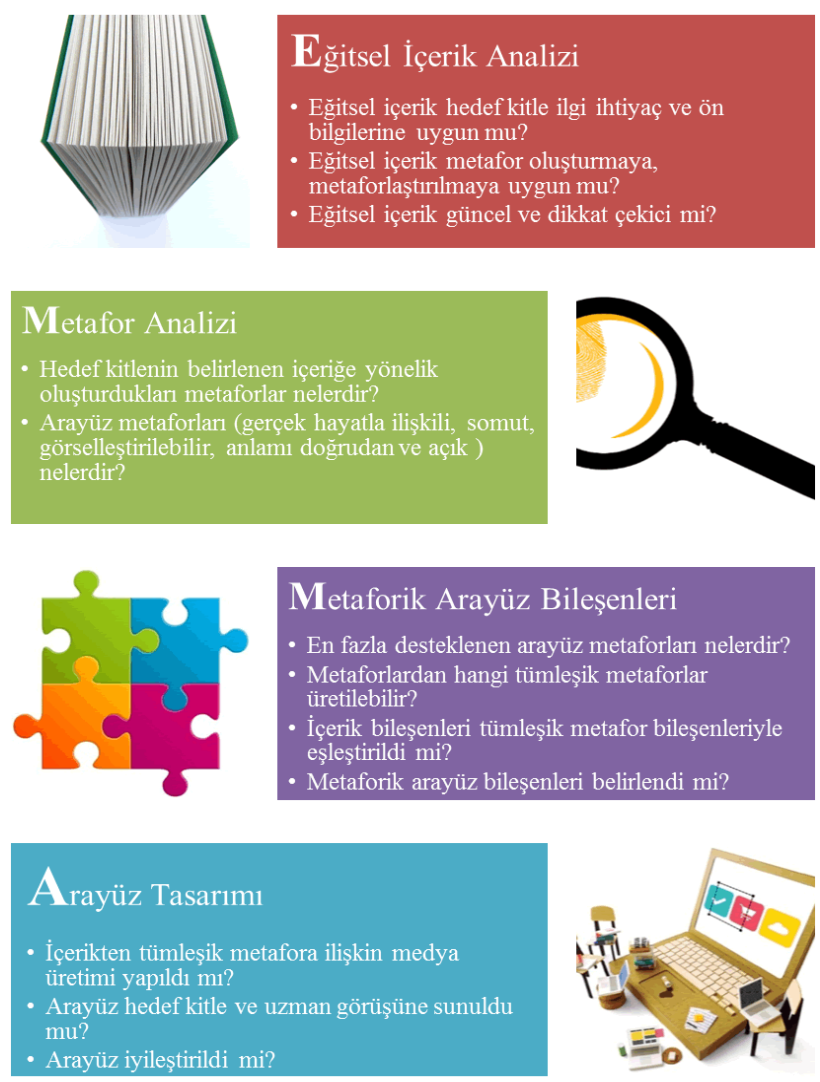

Şekil 8. EMMA'nın Çerçeve Yapısı (Framework of EMMA)

EMMA adımları sadece PC için üretilen eğitsel Hiperortamların tasarımında değil aynı zamanda iPhone, iPad, cep telefonları ve tablet bilgisayar gibi güncel mobil teknolojilerde etkili bir yöntem olarak kullanılabilir. EMMA Adımlarının ayrıntılı adımları aşağıda Tablo 3'te verilmiştir. 
Tablo 3. EMMA Ayrıntılı Adımları (Details of EMMA Steps)

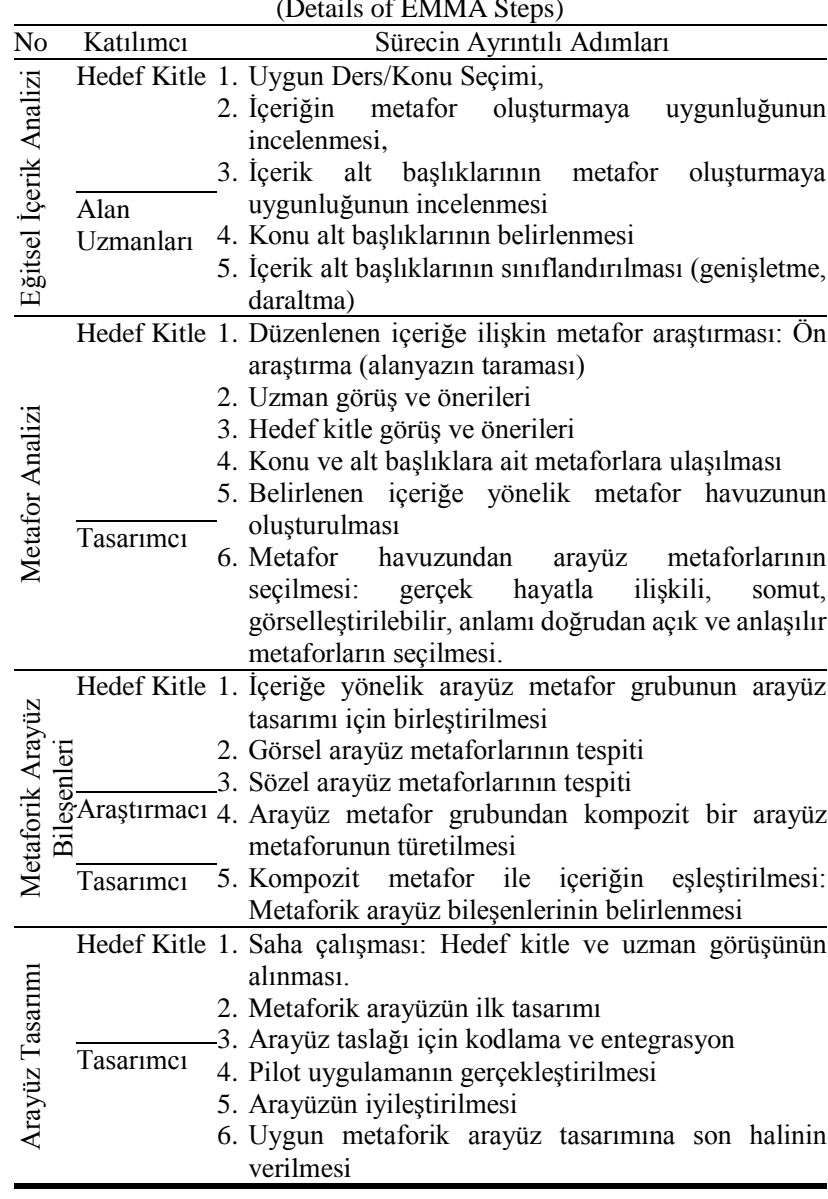

Gerçekleştirilen araştırmalar kapsamında geliştirilen metaforik arayüz tasarım adımları olan EMMA adımlarından yararlanılarak elektronik ortamda gerçekleştirilecek eğitsel çoklu ortam ve Hiperortamlar için metaforik arayüzler geliştirilebilir. Böylece dijital ortamda hazırlanan eğitsel uygulamalarda öğrenenlerin gezinim performansları desteklenerek aşırı bilişsel yüklenme, kaybolma, motivasyon düşüklüğü, zaman kaybı ve vazgeçme problemleriyle başa çıkmalarında destek sağlanabilir. EMMA adımları çerçevesinde eğitsel Hiperortamlarda metaforik arayüzlerin oluşturulmasında dikkat edilmesi gereken üç temel odağın içerik analizi, metafor analizi ve arayüz bileşenlerinin belirlenmesi olduğunu söylemek mümkündür.

3.5. Eğitsel Hiperortamlarda Metafor Kullanımının Pedagojik ve Pratik Çıkarımlarl Nelerdir? (What are Pedagogical and Practical Implications of Metaphor Use in Educational Hypermedia?)

Eğitsel hiper metin, Hiperortam ve çoklu ortamlarda öğrenenlerin yeni, karmaşık veya öğrenilmesi zor ortamları anlama ve bu çevrelere alışmalarını kolaylaştırmak amacıyla metaforlardan yararlanılabileceği görülmektedir [8]. Bunun temel sebebi ise metaforların bilişsel kapasiteleri ve pedagojik özelliğinden kaynaklandığını söylemek mümkündür. Metafor, bir tür şeyi başka bir tür şeye göre anlamak ve tecrübe etmektir [13]. Daha açık olarak metaforlar yeni, karmaşık veya öğrenilmesi zor bir şeyi tanıdık başka bir şeyle açıklamaktır. Bu bağlamda EMMA Adımlarının temel pedagojik çıktısı tanıdık olgular, alışkanlıklar, görevler ve somut nesnelerden yararlanarak eğitsel hiper metin, Hiperortam ve çoklu ortamların görünmeyen soyut fonksiyonlarını kullanıcıya anlaş1lır ve hatırlanabilir hale getirmektir. Böylece EMMA adımları yoluyla iyi yapılandırılmış eğitsel metaforik bir arayüz;

- tanıdık ve sağlam objelere dayanır,

- öğrenenin bilișsel gelişimsel özelliklerine uygundur,

- kullanımına yönelik kural ve prosedürlerin öğrenilmesi gerekmez,

- arayüz bileşenlerinin işlevlerine yönelik ön bilgi veya hazırlık gerektirmez,

- öğrenenin kendi yaşam deneyimlerine dayanır ve

- ortamda verilen enformasyona ilişkin ön örgütleyici rolü oynar,

EMMA Adımları PC, iPhone, iPad, PDA'larda ve cep telefonlarında etkili bir şekilde kullanılabilirler. Metaforik arayüzler, PDA gibi kișisel mobil cihazların kullanılabilirliğini geliştirebilirler. Bu cihazlar için yeni eğitsel uygulamalar oluşturulduğunda metaforik arayüzlerden etkili bir şekilde faydalanılabilir. Bu çalışma kapsamında 2014-2015 güz dönemi İşletim Sistemleri dersine yönelik olarak metaforik bir eğitsel Hiperortam arayüzü geliştirilmiştir. Arayüz Şekil 9'da verilmiştir.

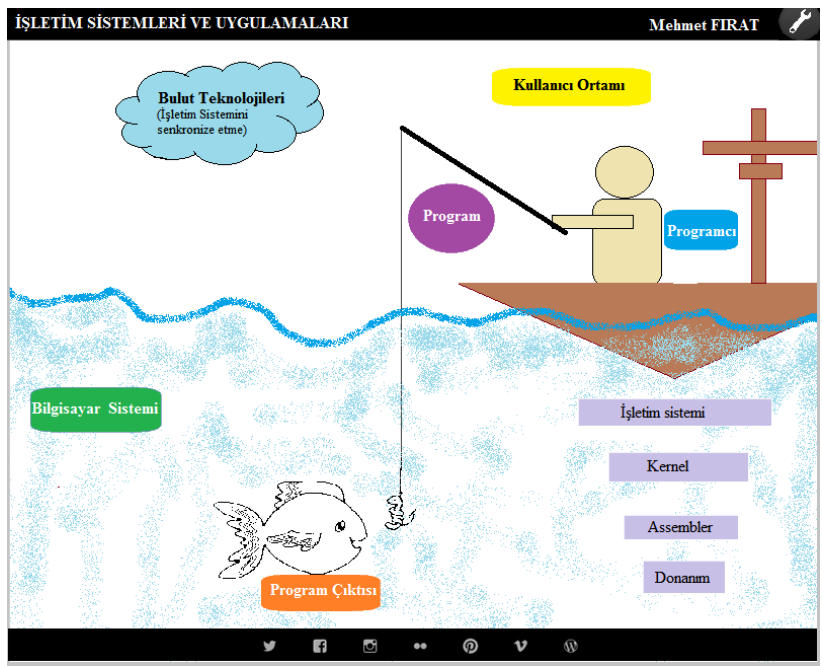

Şekil 9. İşletim Sistemleri dersi için metaforik bir arayüz (a metaphorical interface for Operating Systems course)

Şekil 9'da verilen arayüzde anlaşılacağı gibi İşletim sistemleri katmanları ve ilgili diğer konular tümleşik bir metafor olarak "balık tutma" ile verilmiştir. Tümleşik metaforda işletim sisteminin her biri konusu ilgili bir öğe ile verilmiştir. $\mathrm{Bu}$ arayüzde amaçlandığı gibi kullanıcı arayüz metaforları kullanıcıya arayüzü nasıl kolayca kullanacaklarını anlamada yardımcı olabilirler. Bununla birlikte metaforların arayüzlerde kullanılmasıyla ilgili ön çalışmalar oldukça önemli olup kullanıcı memnuniyetinin 
sağlanması için demografik özelliklerine uygun metaforların tasarıma dâhil edilmesi gerekmektedir [18].

\section{SONUÇ VE ÖNERILER (COCNCLUSION AND SUGGESTIONS)}

$\mathrm{Bu}$ çalışmada eğitsel Hiperortamlarında öğrenenlerin gezinimlerine yönelik bir metaforik arayüz tasarım geliştirme çerçevesi sunulmuştur. EMMA Adımları, araştırmacıların dört yıl boyunca gerçekleştirdikleri çeşitli araştırmaların sonucunda olgunlaşmıştır. Gerçekleştirilen bir dizi araştırma sonucunda ulaşılan EMMA Adımlarının akış şeması Aşağıda Şekil 10'da verilmiştir.

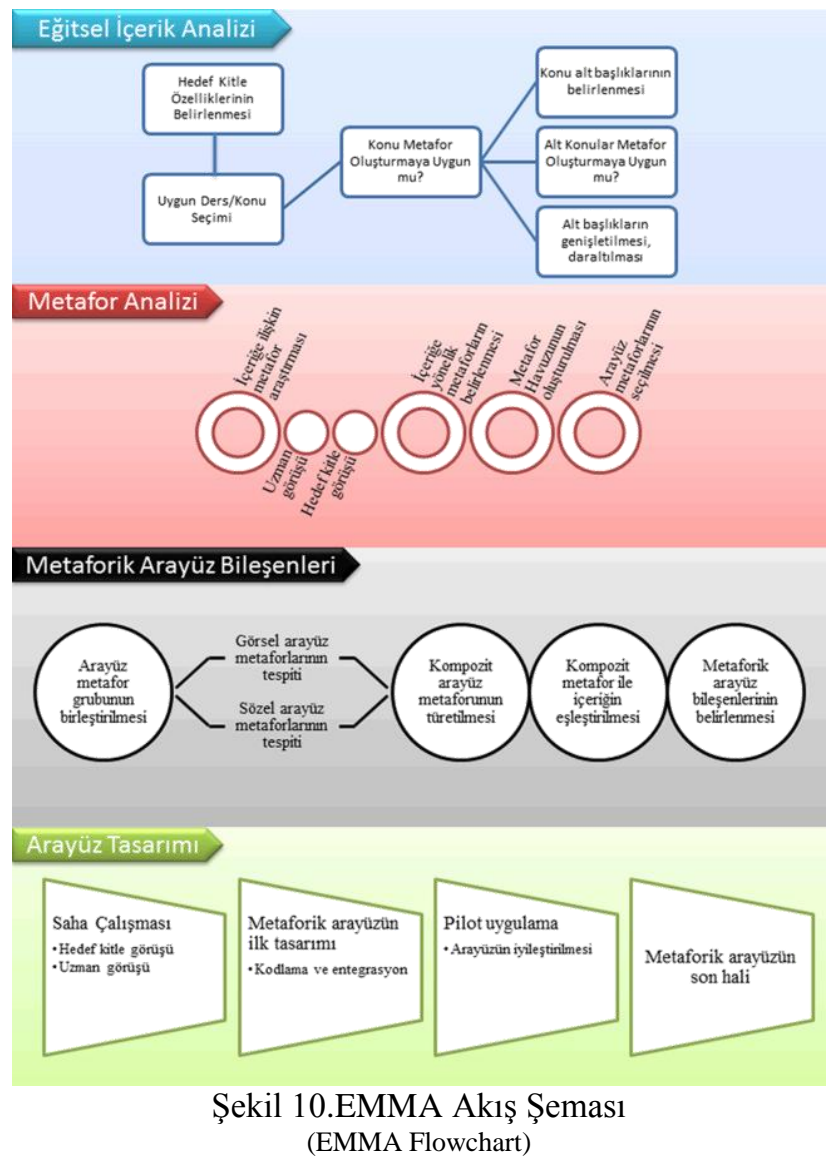

EMMA Adımlarının oluşturulmasındaki temel amaç, öğrenenlerin eğitsel Web ortamlarında karşılaştıkları aşırı bilişsel yüklenme, kaybolma, dikkat bölünmesi, zaman kaybı, motivasyon düşmesi gibi gezinim problemleriyle başa çıkmalarını desteklemektir. Bu bağlamda EMMA Adımlarına yönelik araştırmaların temel çıkış noktası metaforlar yoluyla tanıdık olgular, alışkanlıklar, görevler ve somut nesnelerden yararlanarak yeni, karmaşık veya anlaşılması zor bu dijital eğitsel ortamların öğrenenlere tanıdık, anlaşılır ve hatırlanabilir hale getirilebileceğidir.

EMMA Adımlarına yönelik gerçekleştirilen araştırmalar sonucunda eğitsel Web arayüz tasarımında metafor kullanımına yönelik ulaşılan sonuçlar çerçevenin eğitsel çıktılarının temel dayanaklarını oluşturmaktadır. Beş temel aşama ve bir dizi işlem ve adımdan oluşan EMMA Adımları sadece PC'lerde değil iPhone, iPad, PDA'larda ve cep telefonlarında da eğitsel Web arayüzlerinin tasarımı sürecinde kullanılabilecek bir çerçeve sunmaktadır.

İleride yapılacak araştırmalara yönelik iki farklı öneri geliştirmek mümkündür. Bunlardan ilki EMMA Adımlarına yönelik, ikincisi ise arayüzde metafor kullanımına yöneliktir. EMMA Adımlarına yönelik olarak sürekli gelişen teknoloji ve sunulan olanaklar dikkate alınarak çeşitli araştırmalar yapılabilir. Bu çalışmalar EMMA Adımlarının işlem adımlarından birine yönelik olabileceği gibi geliştirilen yapının genelinde yapılacak güncellemelere yönelik de olabilir. Arayüzde metafor kullanımına yönelik farklı demografik özelliklere sahip katılımcılarla kapsamlı araştırmalar gerçekleștirilebilir. Bu araştırmalar arayüzde kullanılacak metaforların özelliklerine yönelik olabileceği gibi hedef kitle özelliklerinin oluşturduğu farklılıklara yönelik de olabilir.

\section{KAYNAKLAR (REFERENCES)}

[1] G. Jacobs, "Hypermedia and Discovery-Based Learning: A Historical Perspective". British Journal of Educational Technology, 23, 113-121, 1992.

[2] R. Garrison, and T. Anderson, E-learning in the 21 st century: A Framework for Research and Practice. New York: Rutledge Flamer. 2003.

[3] J. Conklin, "Hypertext: An Introduction and Survey". IEEE Computer, 20, 17-41, 1987.

[4] R. Oliver, and H. Oliver, "Information Access and Retrieval With Hypermedia Information Systems". British Journal of Educational Technology, 27: 33-44, 1996.

[5] E. Kılıç, ve Ş. Karadeniz, "Hiperortamlarda Öğrencilerin Bilişsel Yüklenme ve Kaybolma Düzeylerinin Belirlenmesi”. Kuram ve Uygulamada Eğitim Bilimleri, 40, 562-579, 2004.

[6] M. Fırat, ve I. Kabakçı, "Use of Visual Metaphors for Navigation in Educational Hypermedia: Effects on the Navigational Performance". Journal of Educational Multimedia and Hypermedia, 19(1), 5-22, 2010.

[7] P. Barr, User-interface Metaphor in Theory and Practice. MSc. Thesis, Victoria University of Wellington, Department of Mathematical and Computing Sciences. 2003.

[8] P.J. Lynch, "Visual Design for the User Interface". Journal of Biocommunications, 21, 22-30, 1994.

[9] J. Lee, and Y. Hsu, "Visual Metaphor Interface and Cognitive Style: A study for Online Learning”. In L. Cantoni ve C. McLoughlin (Eds.). Proceedings of World Conference on Educational Multimedia, Hypermedia and Telecommunications (pp.4478-4481). Chesapeake, VA: AACE. 2004

[10] J. Cheon, and M.M. Grant, "A cognitive load approach to metaphorical interface design: Reconsidering theoretical frameworks". Proceedings of Society for Information Technology and Teacher Education International Conference, 1054-1059. Chesapeake, VA: AACE. 2008. 
[11] E. Merdivan and N. Özdener, "Effects of different metaphor usage on hypertext learning". Behaviour and Information Technology, 30(2), 273-285, 2011

[12] A. Ortony, Metaphor and Thought (2nd Ed.) Cambridge: Cambridge University Press. 1993.

[13] G. Lakoff, and M. Johnson, Metaphors we live by. Chicago: University of Chicago Press. 1980.

[14] R.G. Malgady and M.G. Johnson, "Measurement of figurative language: Semantic feature models of comprehension and appreciation". In R.P. Honeck and R. R. Hoffman (Eds.). Cognition and figurative language. Hillsdale, NJ: Erlbaum. 1980.

[15] M. Firat and I. Kabakçı Yurdakul, "Metaphores in metacommunication". In Meta-Communication for Reflective Online Conversations: Models for Distance Educations, Ed.: U. Demiray, G Kurubacak ve T. V. Yuzer, Hershey, PA: Information Science Reference, 2011
[16] M. Fırat and I. Kabakçı Yurdakul, "Determining the Variables of Instructional Hypermedia Navigation Performance". e-Journal of New World Sciences Academy NWSA-Education Sciences, 1C0494, 7, (1), 296-304, 2012.

[17] M. Fırat, Eğitsel Hiperortamlarda Metaforik Arayüzlerin Bilişim Teknolojileri Öğretmen Adaylarının Gezinim Performansına Etkileri. Doktora Tezi, Anadolu Üniversitesi, Eğitim Bilimleri Enstitüsü, Eskişehir, 2012.

[18] D.S. Catre, Visualization of Interface Metaphor for Software: An Engineering Approach. Baco Raton, USA: Florida, 2011.

[19] P. Kilgore, M., Trutschl, and U. Cvek, "Panoramic Interaction with Interval Data Based on the Slider Metaphor." In ACHI 2014, The Seventh International Conference on Advances in Computer-Human Interactions, (pp. 271-276), March 2014.

[20] M. Ishihara \& Y. Ishihara, "Fishing Metaphor for Navigation in CAVE." HCI International 2014-Posters' Extended Abstracts. Springer International Publishing, 2014. 596-601. 